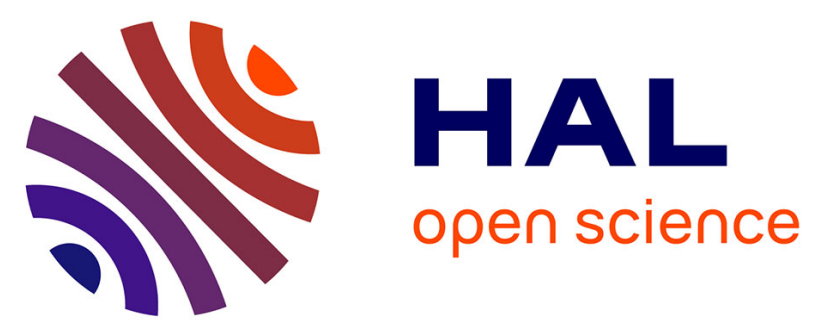

\title{
Mulch of plant residues at the soil surface impact the leaching and persistence of pesticides: A modelling study from soil columns
}

Sohaib Aslam, Akhtar Iqbal, Francois Lafolie, Sylvie Recous, Pierre Benoit, Patricia Garnier

\section{To cite this version:}

Sohaib Aslam, Akhtar Iqbal, Francois Lafolie, Sylvie Recous, Pierre Benoit, et al.. Mulch of plant residues at the soil surface impact the leaching and persistence of pesticides: A modelling study from soil columns. Journal of Contaminant Hydrology, 2018, 214, pp.54-64. 10.1016/j.jconhyd.2018.05.008 . hal-01818263

\section{HAL Id: hal-01818263 \\ https://hal.science/hal-01818263}

Submitted on 26 May 2020

HAL is a multi-disciplinary open access archive for the deposit and dissemination of scientific research documents, whether they are published or not. The documents may come from teaching and research institutions in France or abroad, or from public or private research centers.
L'archive ouverte pluridisciplinaire HAL, est destinée au dépôt et à la diffusion de documents scientifiques de niveau recherche, publiés ou non, émanant des établissements d'enseignement et de recherche français ou étrangers, des laboratoires publics ou privés.

\section{(ㅇ)(1) $\$$}

Distributed under a Creative Commons Attribution - NonCommercial - NoDerivatives 44.0 


\section{Accepted Manuscript}

Mulch of plant residues at the soil surface impact the leaching and persistence of pesticides: A modelling study from soil columns

Sohaib Aslam, Akhtar Iqbal, François Lafolie, Sylvie Recous, Pierre Benoit, Patricia Garnier

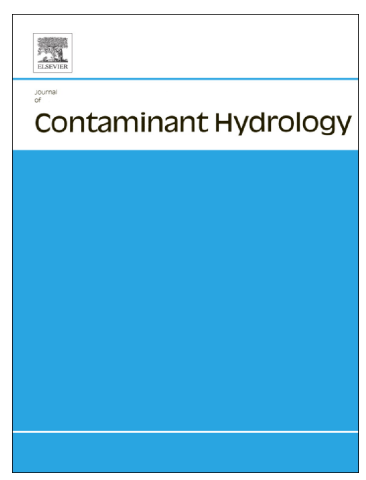

PII: S0169-7722(17)30364-9

DOI: doi:10.1016/j.jconhyd.2018.05.008

Reference: CONHYD 3398

To appear in: Journal of Contaminant Hydrology

Received date:

7 December 2017

Revised date: 25 May 2018

Accepted date:

29 May 2018

Please cite this article as: Sohaib Aslam, Akhtar Iqbal, François Lafolie, Sylvie Recous, Pierre Benoit, Patricia Garnier, Mulch of plant residues at the soil surface impact the leaching and persistence of pesticides: A modelling study from soil columns. Conhyd (2017), doi:10.1016/j.jconhyd.2018.05.008

This is a PDF file of an unedited manuscript that has been accepted for publication. As a service to our customers we are providing this early version of the manuscript. The manuscript will undergo copyediting, typesetting, and review of the resulting proof before it is published in its final form. Please note that during the production process errors may be discovered which could affect the content, and all legal disclaimers that apply to the journal pertain. 


\section{Mulch of plant residues at the soil surface impact the leaching and persistence of pesticides: a modelling study from soil columns}

Sohaib Aslam, ${ }^{\mathrm{a}, \mathrm{d}}$, Akhtar Iqbal ${ }^{\mathrm{b}, \mathrm{e}}$, François Lafolie $^{\mathrm{c}}$, Sylvie Recous ${ }^{\mathrm{b}}$, Pierre Benoit ${ }^{\mathrm{a}}$, Patricia Garnier $^{\mathrm{a}^{*}}$

${ }^{a}$ INRA, UMR ECOSYS, Université Paris-Saclay, 78850 Thiverval-Grignon, France

bINRA, UMR FARE, 51686 Reims, France

'INRA, UMR EMMAH, Site Agroparc, 84914 Avignon Cedex 9, France

dINRA, Forman Christian College, Lahore 54600, Pakistan

${ }^{\mathrm{e}}$ INRA, COMSATS Institute of Information Technology, Abbottabad 22060, Pakistan

*Corresponding author 


\section{Abstract}

Crop residues left on the soil surface as mulch greatly influence the fate of pesticides in conservation agricultural practices because most of the applied pesticide is intercepted by mulch before passing to the soil. Modelling of pesticide losses from wash-off and leaching will greatly improve our understanding of the environmental consequences of pesticides in these systems. The PASTIS model, which simulates water transfer, mulch decomposition, and pesticide dynamics, was adapted in this new version to model the interactions between pesticides and mulch in order to simulate the impact of mulch on pesticide dynamic. Parameters of mulch dynamics and pesticide degradation and retention processes were estimated using independent incubation experiments. The PASTIS model was tested with experimental laboratory data that were obtained from two pesticides (Glyphosate and s-metolachlor) applied to soil columns where mulch composed of maize and dolichos was placed at the soil surface impacted by two rain intensities (a high and infrequent intensity and a light and frequent intensity). Simulations indicated good agreement between simulated and experimental values. After 1 day, 45-46\% of the pesticides leached from the mulch and 54-55\% remained in the mulch for both pesticides and both rain intensities. During the experiment, pesticide wash-off was greater for the high and infrequent rain (56-57\%) compare to light and frequent rain (39-45\%) for both pesticides. A smaller amount of S-metolachlor washed off with the light and frequent rain intensity (39\%) than glyphosate $(45 \%)$ because of its lower desorption rate from mulch residues. Glyphosate was more degraded (37-45\%) than s-metolachlor (17-37\%), which agrees with preliminary incubation experiments that were used for parameter estimation. A sensitivity analysis indicated that the saturation index of mulch at which pesticides started their diffusion in the rainwater and the time of the first rainfall were the two parameters that influenced the most output variables of our model. This study suggests that the PASTIS model developed for pesticide dissipation in mulch is a useful tool to evaluate the potential risk of pesticide leaching to the groundwater in conservation agriculture systems.

\section{Keywords}

Maize; Dolichos; Glyphosate; S-metolachlore; Transport; Dissipation 


\section{Introduction}

Conservation agricultural techniques have gained much attention in recent decades because of their role in conserving water and soil resources. Mulches made of crop residues from harvest or cover crops provide many beneficial services such as soil moisture retention, high biological activity at the soil surface and carbon storage (Rabary et al., 2008). In addition, these organic residues intercept, retain, and strongly modify the fate of pesticides (Locke and Bryson, 1997). Dissipation processes of pesticides, such as degradation, sorption and transport, are greatly influenced at the soil surface because of the presence of mulch residues (Alletto et al, 2010). Mulch characteristics, including its quality and degree of decomposition, and the timing of the first rainfall after pesticide application greatly influence pesticide retention and wash-off (Dao, 1991; Granovsky et al., 1994; Gaston et al., 2001). Aslam et al. (2013) suggested that the adsorption of pesticides was associated with the chemical composition of crop residues. The characteristics of the origin and decomposition degree of crop residues have also been reported to influence pesticide degradation (Rampoldi et al., 2008; Aslam et al., 2014).

Many pesticide models have been developed and tested to predict pesticide fate in soils considering biotic and abiotic processes (FOCUS, 2006). However, little attention has been given to the development of models for pesticide fate that could simultaneously account for the presence of mulch. Geng et al. (2015) and Brimo et al. (2018) recently developed a model that simultaneously accounts for the transformation of organic matter that is added to soil as compost and organic pollutant dynamics. Aslam et al. (2014) simulated glyphosate dynamics in mulch composed of maize during its decomposition by using ${ }^{14} \mathrm{C}$-labeled pesticide molecules. The model did not consider pesticide transfer that occurred from wash-off from mulch into the soil. On the other hand, other models $\left(\mathrm{TEC}_{\text {mulch }}\right.$, SiSPAT) were developed to predict the impact of surface mulch residues on physical processes such as the soil thermal regime, water run-off and erosion (Enrique et al., 1999; Findeling et al., 2003). Findeling et al. (2007) and Coppens et al. (2007) have combined water dynamic with the biotransformation of $\mathrm{C}$ and $\mathrm{N}$ in soil to predict the decomposition of mulch residues at the soil surface. They showed that rain intensity impacts water retention in mulch and, consequently, its decomposition. Additionally, Iqbal et al. (2013) showed that the water retention in mulch residues depends partially on their physical and chemical characteristics (e.g., origin and decomposition degree). Previously, Ma and Selim (2005) proposed a two-site-equilibrium-kinetic model for predicting the retention and transport 
of reactive solutes in soil. After estimating the sorption parameters, they successfully simulated the movement of atrazine in soil columns mixed with mulch residues. However, their model was unable to account for the biological processes of dissipation, and moreover, they used a uniform mixture in their modelling approach rather than considering a mulch/soil layered system, as is characteristic in conservation agriculture. Lammoglia et al. (2016) coupled the pesticide model MACRO with the crop model STICS to simulate the transport of pesticides in various crop management practices. They showed that the presence of mulch has a strong impact on pesticide leaching. However, the mulch module was not calibrated and tested with experimental data.

The objective of this study was to develop a new model that was able to simultaneously simulate the presence of mulch, its decomposition, and its impact on the leaching of pesticides when applied at the soil surface. We tested the model with published data from soil column experiments using two widely used herbicides, glyphosate and S-metolachlor. We analysed the sensitivity of the model output to different input parameters and initial conditions.

\section{Materials and methods}

\subsection{Description of PASTIS Model}

The PASTIS (Prediction of Agricultural Solute Transformations In Soils) model simulates the movement of water and the transformation of solutes in soil and was further described by Garnier et al. (2003) to simulate decomposition in straw-amended soils. The model consists of a 1-D transport module (using Richards' equation for water flow and the convection-dispersion equation for solute movement) and a transformation $\mathrm{C} / \mathrm{N}$ module, CANTIS (Carbon and Nitrogen Transformations In Soil). The model simulated the mulch decomposition (Coppens et al., 2007) and pesticide transport (Saffih-Hadadi, 2003), independently. In this study we linked the mulch module and the pesticide module in order to simulate the pesticide dynamic in mulch.

\subsubsection{Description of Mulch dynamic in PASTIS}

Pastis simulates the impact of mulch on rain interception and on the reduction of water evaporation (Findeling et al., 2003). Mulch intercept rain water and stores it as a porous medium according to its physical properties like maximal and residual volumetric water content, mulch propensity to water recharge as described in details in Findeling et al. (2003). The amount of water that is not intercepted by the mulch is transmitted to the soil. For evaporation, the mulch acts as a physical barrier to convective and diffusive vapour fluxes between the soil and the 
atmosphere. As a consequence, the total potential evaporation rate is split into the potential evaporation rate of the mulch and the soil using the coefficient of water evaporation. Potential evaporation rate of the mulch is applied to the mulch to evaporate its water storage.

Findeling et al. (2007) extended the model to consider mulch residues decomposition at the soil surface. Mulch is divided in two layers as described in APSIM-Residue (Thorburn et al., 2001): i) only the mulch layer that is directly in contact with the soil can be degraded by soil microorganisms (we found a height of few $\mathrm{mm}$ in Findeling et al, 2007); and ii) the mulch layer that is just above the first layer is not subjected to decomposition and is supposedly inaccessible to soil micro-organisms. The upper part of the mulch can become closer to the soil either because of the decomposition of the lower part or because of external factors like management, rain, wind... In our column study, the upper mulch layer is assumed to feed the bottom layer because of the bottom layer degradation. Findeling et al. (2007) defined these two mulch compartments as:

$$
D M_{m}(t)=D M_{m, c}(t)+D M_{m, n c}(t)
$$

where the $D M_{m, c}$ and $D M_{m, n c}$ terms represent the mulch dry mass $\left(\mathrm{kg} \mathrm{m}^{-2}\right)$ that is in contact and not in contact with soil, respectively. The mulch residue mass that is decomposed in $D M_{m, c}$ is replaced by a superficial layer, and this replenishment is regulated by an empirical factor. $D M_{m, n c}$ is set to an initial value that decreases exponentially with time and corresponds to an equivalent increase in $D M_{m, c}$ as:

$$
\Delta D M_{m, c}(t)=\alpha_{f e e d} D M_{m, n c}(t) \Delta t
$$

where $\alpha_{\text {feed }}\left(\mathrm{d}^{-1}\right)$ is the extinction coefficient of $D M_{m, n c}$ and describes the feeding rate of the decomposable mulch compartment by the non-decomposable mulch compartment. Decomposition of the contact mulch compartment $D M_{m, c}$ is simulated by the CANTIS submodel (Garnier et al., 2003) that divides $D M_{m, c}$ organic matter into four pools, including readily decomposable material (RDM), hemicellulose (HEM), cellulose (CEL) and lignin (LIG). CANTIS also considers two microbial compartments: one that decomposes the humified organic matter and the other that decomposes the fresh organic matter; in this case, the mulch is in contact with the soil. In order to decompose the organic matter of mulch generally poor in nitrogen like in most crop residues, nitrogen should be provided by the soil. We found in our previous study (Findeling et al., 2007) that the depth of soil that provided the mineral nitrogen for microbial degradation was between 1 and $5 \mathrm{~cm}$ depending on the $\mathrm{C}: \mathrm{N}$ of the residues. 
The CANTIS module was slightly modified to account for changes in mass and composition due to soluble carbon that leaches during rains. When feeding occurs, the composition of the new decomposable layer was calculated according to its own previous composition and the composition of the added organic matter coming from the non-decomposable layer. In the CANTIS module, decomposition rates obey first-order equations, with rates depending on water potential and temperature. Hence, water potential and temperature of the mulch contact layer (Mc) must be simulated.

\subsubsection{Description of pesticide dynamic in PASTIS}

Saffih-Hdadi et al. (2003) implemented a pesticide module in PASTIS. This module considers pools of pesticide and its metabolites such as water soluble $\left(P_{\mathrm{w}}, M_{\mathrm{w}}\right)$, weakly or reversibly adsorbed $\left(P_{\mathrm{ads}}, M_{\mathrm{ads}}\right)$, and irreversible adsorbed or non-extractable residues, NER in the following $\left(P_{\mathrm{NER}}, M_{\mathrm{NER}}\right)$. Pesticide distribution between these compartments is described as a kinetic process (Shelton et al., 1997; Saffih-Hdadi et al., 2003). Pesticide degradation assumes co-metabolism. Pesticide of the soluble phase is degraded through a first-order kinetic equation and depends on the pesticide concentration in the soluble pool $\left(P_{\mathrm{w}}\right)$, the degradation coefficient $\left(D_{\mathrm{rp}}\right)$ and the microbial biomass $(X)$ as:

$$
\left(\frac{d P_{\mathrm{w}}}{d t}\right)=-D_{\mathrm{rp}} X P_{\mathrm{w}}
$$

Biodegradation of pesticide is considered to be either complete or partial, resulting in the production of major metabolites. Pesticide degradation used the same limiting functions of temperature and humidity as those used for organic matter (Garnier et al, 2003). Metabolites are produced into a soluble phase, and their degradation and distribution between three pools are described similarly as for the parent pesticide (Table S1: Supplementary Material). The equations for the pesticide dynamics are presented in Table S1: Supplementary Material.

\subsubsection{Description of the interactions between mulch and pesticide in PASTIS}

In this study, a new version of the model was developed to simulate the impact of mulch on pesticide fate, by coupling the pesticide sub-model (Saffih-Hdadi et al., 2003) to the mulch submodel PASTIS (Findeling et al., 2007). All pesticide pools (soluble, adsorbed, etc.) of mulch residues were distributed in the mulch layer that was in contact with soil and the upper mulch 
layer (Figure 1). Pesticide degradation is assumed only in the first mulch layer, in contact with the soil. Pesticides in the upper layer can only be adsorbed but are not degraded because we assumed they are unreachable for the soil microorganisms. Other types of degradation may occur in the upper layer like photo degradation, but we assumed it was neglectable and it was not considered in the model. The same microbial biomass, as the one calculated by CANTIS for decomposing mulch, was also considered for pesticide degradation by co-metabolism (using measurement at initial time). When the decomposition of organic matter occurs, the microbial biomass increases and, therefore, the rate of pesticides degradation also. Indeed, some authors have shown that glyphosate biodegradation was performed co-metabolically and that the decomposition rate depends on the general activity of soil microorganisms (Gimsing et al., 2004). The results of Alletto et al. (2013) from incubation experiments of SMOC indicated also a probable degradation by unspecialized populations. In addition, the microbial biomass can also contribute to NER formation as described in Lashermes et al. (2013).

Pesticide from the soluble pool of mulch (the contact and non-contact mulch layers) diffuses into rain water that transfers through the mulch. The process is described by the following equation:

$$
\frac{d C}{d t}=-D_{p} C
$$

where $C\left(\mathrm{~g} \mathrm{~L}^{-1}\right)$ is the pesticide concentration and $D_{p}\left(\right.$ day $\left.^{-1}\right)$ is the diffusion coefficient of pesticide between the water of mulch and the rain water. This equation of diffusion is valid after the mulch reaches a certain level of humidity (i.e., $S_{i}\left(\mathrm{~cm}^{3} \mathrm{~cm}^{-3}\right)$ ), which is the saturation index of mulch from which diffusion of pesticides can occur. Pesticides emitted from mulch enter into the soil through the process of wash-off at each rainfall. 


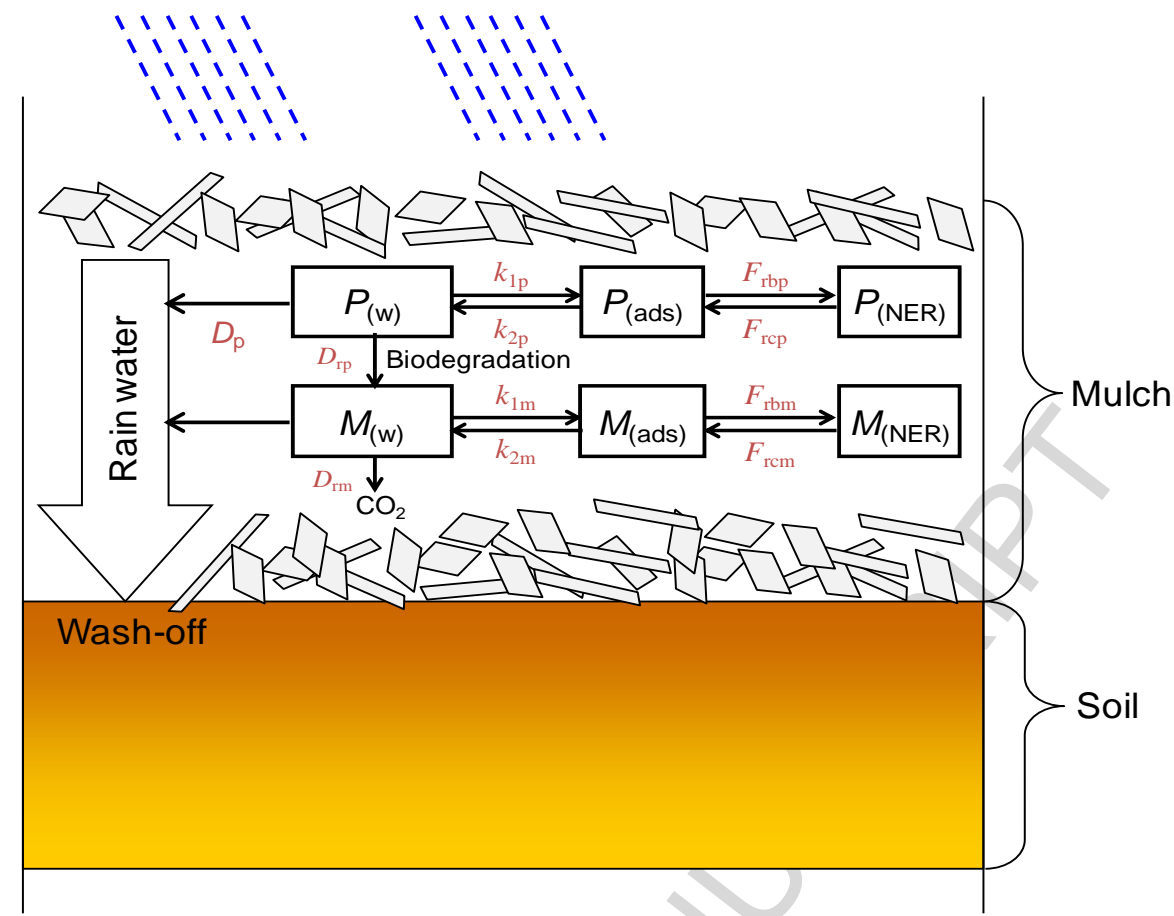

Figure 1. Schematic diagram of the pesticide module in mulch. Pesticide compartments of soluble (w), adsorbed (ads) and non-extractable residues (NER) of the parent molecule (P) and metabolite (M) are represented. The soluble compartment diffuses in rain water and can leach into soil below the mulch.

\subsection{Experimental set up}

The detailed protocol of column experiments that were conducted to calibrate and test the model was previously reported in Aslam et al. (2014). A summary of the experimental protocol is presented here.

\subsubsection{Soil and mulch sampling}

The soil used in this study was sampled from the experimental site of INRA, near Versailles, France. Soil sampling was performed from 0-5 cm and 5-25 cm layers, and the soil was sieved $(<$ $4 \mathrm{~mm}$ ) in order to have better replicates between columns. Crop residues that were used as mulch were mature residues (consisting of leaves, stalks, and branches) of maize (Zea mays) and dolichos (Lablab dolichos) that were chopped into 2-3 cm-long pieces. Mulch from these residues was prepared with a calculated proportion of $63 \%$ maize (60\% stems and $40 \%$ leaves) and $37 \%$ dolichos (87\% stems and $13 \%$ leaves), which was observed in the field. 


\subsubsection{Experimental protocol (Aslam et al., 2015)}

PVC cylinders (i.d. of $15.4 \mathrm{~cm}$ and height of $35 \mathrm{~cm}$ ), with a small drainage outlet at their base, were filled with $25 \mathrm{~cm}$ of the soil that was sampled from two depths $(0-5$ and $5-25 \mathrm{~cm})$. The humidity of the soils was adjusted to $\mathrm{pF} 2.5$ before their insertion into the columns. Mulch residues (14.1 g equivalent dry mass corresponding to a biomass of $7.6 \mathrm{t} / \mathrm{ha}$ ) were pre-humected and placed homogenously on the soil surface. After mulch placement, the pesticide solution (10 $\mathrm{mL})$ containing both $\mathrm{S}$-metolachlor $\left(0.193 \mathrm{gL}^{-1}\right)$ and glyphosate $\left(0.240 \mathrm{gL}^{-1}\right)$ (corresponding to active ingredient doses of $1.29 \mathrm{~kg}$ glyphosate $\mathrm{ha}^{-1}$ and $1.04 \mathrm{~kg} \mathrm{~S}$-metolachlor ha ${ }^{-1}$ ) was manually applied homogeneously at day 1 . Columns were moved to the incubation room, where they were incubated at $20{ }^{\circ} \mathrm{C}$ in the dark for 84 days. To monitor pesticide dynamics, artificial rain (distilled water) was applied using rain simulators throughout the experiment. Two rainfall regimes were established on the basis of weather patterns of temperate and tropical climates. "Light and frequent rain" (LF-R) was applied two times per week at $6 \mathrm{~mm} \mathrm{hr}^{-1}$ for 20 minutes (2 $\mathrm{mm}$ of water at each rainfall event), thus delivering a total of $16 \mathrm{~mm}$ of water per month. "Heavy and infrequent rain" (HI-R) was applied every two weeks at $20 \mathrm{~mm} \mathrm{hr}^{-1}$ for 24 minutes (8 mm of water at each rainfall event), also delivering a total of $16 \mathrm{~mm}$ of water per month. The total amount of rain water applied in the two treatments was the same at the end of the experiment. Soil columns were weighed before and after each rainfall event to calculate the amount of water lost through evaporation. A total of 24 rain events for frequent (LF-R) and only 6 rain events for infrequent (HI-R) treatment occurred with corresponding numbers of wetting and drying periods. The first rain was applied at day 1, two hours after the application of pesticides. The applications of rain allowed us to obtain soil solutions and to determine the pesticide concentrations at the three depths of the columns. No leachate was observed at the bottoms of the columns because rain application at each rain event replaced the amount of water lost by evaporation without the addition of excess water. A total of 25 columns were incubated for destructive sampling and continuous sampling.

Three additional columns were also prepared for destructive sampling at day 1, just after the pesticide application. These columns did not receive any rainfall and were prepared to measure the amounts of pesticides that were initially intercepted by mulch residues and the amounts that reached the soil beneath. Columns in triplets were sacrificed for destructive sampling at 14, 42 and 84 days after the start of the experiment. At each sampling date, mulch 
residues were collected from the soil surface, and a sub-sample was analysed for pesticide molecules while the remaining mulch was oven-dried at $45{ }^{\circ} \mathrm{C}$. The soil in the columns was sliced into three layers: top 0-5 cm, and bottom 5-15 cm, and 15-25 cm. Pesticide analyses were performed on soil sub-samples from each layer. The gravimetric water content of mulch residues and soil in each layer was also determined at the time of sampling. The total $\mathrm{C}$ and $\mathrm{N}$ contents of the soil and the recovered mulch residues were measured. Collected mulch residues were also characterized with biochemical fractionation (soluble, hemicelluloses, cellulose and lignin fractions). At 3 and $15 \mathrm{~cm}$ depths in the column, water potentials were measured with tensiometers, and volumetric water contents were measured with soil moisture sensors in order to monitor the water transport dynamics. Pesticides and their metabolites in the soil and mulch extracts were analysed. Experimental conditions for this modelling study are summarized in Table 1.

Table 1. Experimental conditions for the two rainfall treatments.

\begin{tabular}{|c|c|c|}
\hline Description of experimental conditions & $\begin{array}{c}\text { Light and } \\
\text { Frequent } \\
\text { Rainfall }\end{array}$ & $\begin{array}{c}\text { Heavy and } \\
\text { Infrequent } \\
\text { Rainfall }\end{array}$ \\
\hline Temperature $/{ }^{\circ} \mathrm{C}$ & 20 & 20 \\
\hline Duration of incubation experiment/days & 84 & 84 \\
\hline Number of rainfall events & 24 & 6 \\
\hline Intensity of rain applied $/ \mathrm{mm} \mathrm{hr}^{-1}$ & 6 & 20 \\
\hline Amount of rain water applied at each event $/ \mathrm{mm}$ & 2 & 8 \\
\hline Total amount of rainwater applied $/ \mathrm{mm}$ & 48 & 48 \\
\hline Interval between two rainfall events/days & $3-4$ & 14 \\
\hline Time of the first rain after pesticide application $/ h$ & 2 & 2 \\
\hline Amount of soil $/ \mathrm{kg}$ column $^{-1}$ & 6.8 & 6.8 \\
\hline Amount of mulch residues added $/ g m^{-2}$ & 758 & 758 \\
\hline Mulch thickness/cm & 3 & 3 \\
\hline Amount of $\mathrm{C}$ added by residues $/ g$ column $^{-1}$ & 6.2 & 6.2 \\
\hline Amount of $\mathrm{N}$ added by residues $/ g$ column $^{-1}$ & 0.104 & 0.104 \\
\hline Glyphosate applied directly on mulch/g $\mathrm{m}^{-2}$ & 0.129 & 0.129 \\
\hline S-metolachlor applied directly on mulch/g $\mathrm{m}^{-2}$ & 0.104 & 0.104 \\
\hline
\end{tabular}

\subsection{Modelling procedure}

The modelling procedure consists of 3 steps (Figure 2): i) the determination of the input parameters for the biological and chemical transformation and for the transport module, ii) the 
testing of the model for the dynamics of pesticides and iii) a sensitivity analysis of the model for the key parameters that describe the leaching of pesticides from mulch.

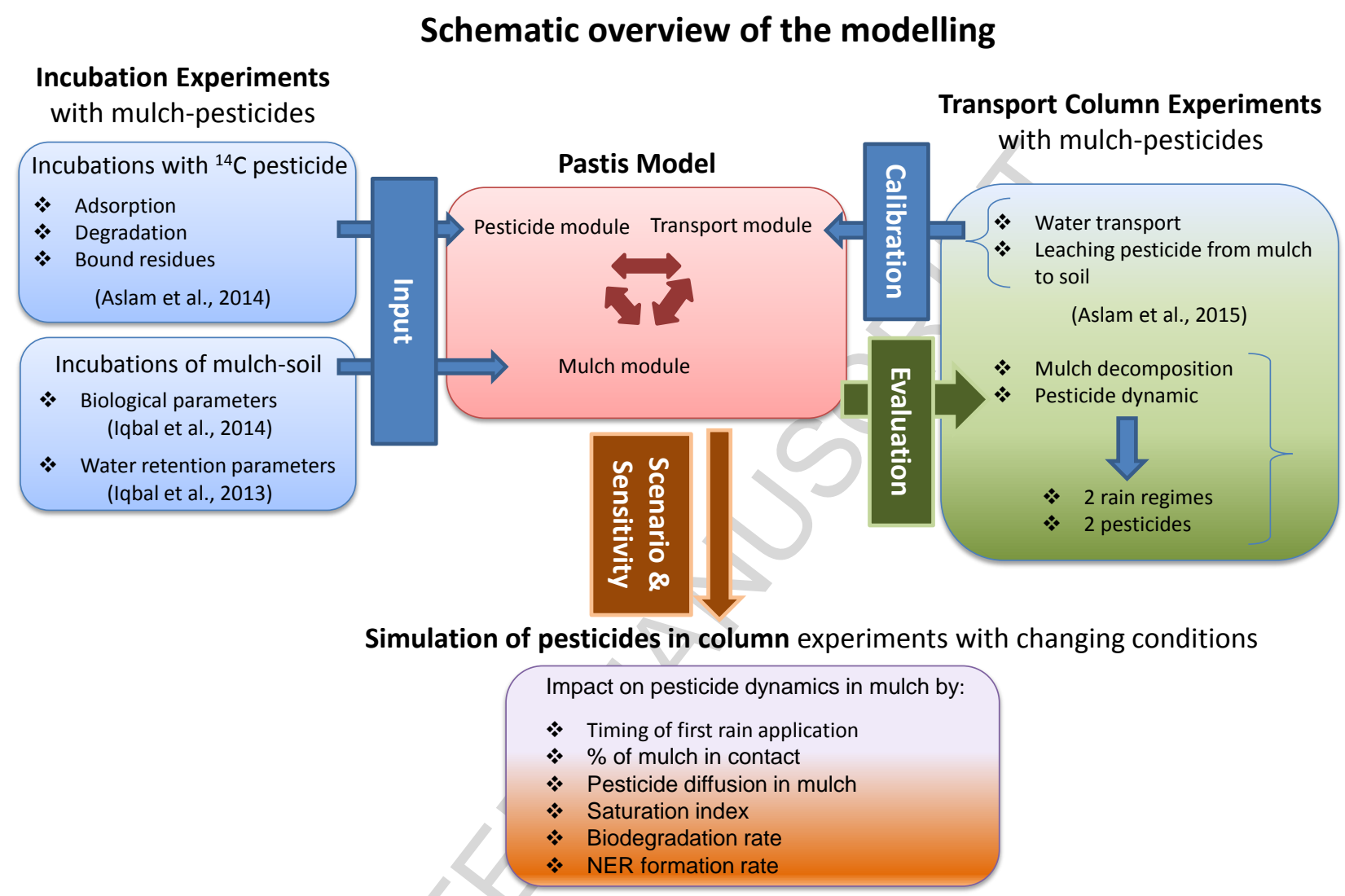

Figure 2. Schematic diagram of the modelling procedure used in this study.

\subsubsection{Input parameters obtained from published laboratory experiments}

Pastis modules were linked to inverse methods based on Levenberg-Marquadt algorithm. All the fittings of this section were carried out using this method.

\section{a) Mulch decomposition parameters}

Biological parameters for the decomposition of mulch and soil organic matter (Table S2) were taken from Iqbal et al. (2014). The CANTIS sub-model was used after fitting the model to experimental data that were obtained and described in detail by Iqbal et al. (2014). Decomposition of maize residues that were incorporated in the soil was monitored in the 
laboratory incubations at $25{ }^{\circ} \mathrm{C}$ for 301 days. The mineralized carbon of the maize residues and their biochemical fractionations were determined at regular intervals during the decomposition. These data were fitted with the CANTIS model (Garnier et al., 2003) to calibrate six parameters using Levenberg-Marquadt algorithm.

\section{b) Pesticide transformation parameters}

Parameters of glyphosate were taken from Aslam et al. (2014), who performed incubation experiments for mulch that was amended with ${ }^{14} \mathrm{C}$-labelled glyphosate. Experimental data corresponding to the mineralized, soluble fractions and extractable and non-extractable residues were calibrated by coupling the mulch decomposition and pesticide degradation modules (see $\S$ 2.1.3). Dissipation parameters of the parent molecule and metabolites were obtained from the mulch compartment. In the soil, only the parent molecule parameters were estimated because of the low amounts of metabolites in the soil layer. Therefore, a total of 10 parameters for the mulch layer and 5 parameters for the soil layer were obtained using 16 experimental curves (Aslam et al., 2014).

Parameters for the S-metolachlor degradation and sorption were estimated from incubation experiments (Hatier, 2012) following the same protocol as used for glyphosate that is reported by Aslam et al. (2014). Briefly, PVC cylinders $(5.6 \mathrm{~cm}$ i.d. and $6 \mathrm{~cm} \mathrm{~h})$ containing soil and maize residues were incubated in the laboratory. After sampling, the soil was sieved at $5 \mathrm{~mm}$ and was stored in plastic bags at $4{ }^{\circ} \mathrm{C}$ before the incubation experiment. Maize residues were cut into small pieces with $1 \mathrm{~cm}$ dimensions. In each cylinder, soil was first placed at the bottom at $1.2 \mathrm{~g}$ $\mathrm{cm}^{-3}$ and at $\mathrm{pF} 2.5$ and was covered by maize residues ( $2 \mathrm{~g}$ dry-equivalent). Samples were preincubated for 6 days before the application of S-metolachlor in order to allow for the adaptation of microorganisms to the incubation conditions. A solution ${ }^{14} \mathrm{C}$-labelled $\mathrm{S}$-metolachlor $(2 \mathrm{~mL})$ corresponding to an agronomic dose of $0.98 \mathrm{~kg} \mathrm{ha}^{-1}$ was homogenously applied to the maize residues in each sample using a micropipette. Incubation was carried out in the dark at $28{ }^{\circ} \mathrm{C}$ for 84 days. Total carbon mineralization was quantified by analysing $\mathrm{C}-\mathrm{CO}_{2}$ colorimetrically using a continuous flow analyser (Skalar, Breda, The Netherlands). Samples, in triplets, were sacrificed at five days for destructive sampling (i.e., $0 \mathrm{~d}, 7 \mathrm{~d}, 22 \mathrm{~d}, 49 \mathrm{~d}$ and $84 \mathrm{~d}$ ). For each sampling date, maize residues and soil at the immediate contact $(0-1 \mathrm{~cm})$ were sampled and stored separately for 
determining the S-metolachlor extractable and non-extractable residues. From each cylinder, $1 \mathrm{~g}$ of maize residue and $25 \mathrm{~g}$ of soil were sampled for sequential (single water and three methanol) extractions. After successive extractions, the radioactivity content in each soil and mulch sample corresponding to non-extractable ${ }^{14} \mathrm{C}$ residues was measured by combustion in a Sample Oxidizer 307 (Packard, Meriden, CT, USA), and the ${ }^{14} \mathrm{CO}_{2}$ that evolved after combustion was measured by liquid scintillation counting. Moreover, mulch and soil extracts that had a sufficient radioactivity level were analysed by high-performance liquid chromatography (HPLC). Smetolachlor and its metabolites were identified in the maize mulch only (Hatier, 2012). Pesticide degradation in the mulch and soil layers was simulated according to Aslam et al. (2014) for glyphosate dynamics. Figure S1: Supplementary Material shows simulations of S-metolachlor degradation and metabolite formation in the mulch layer. Estimated parameters of S-metolachlor sorption and the degradation kinetics in mulch and soil are also presented in Table 2.

Table 2. Degradation and adsorption parameters for the parent pesticide and metabolites in mulch residues and soil.

\begin{tabular}{|c|l|l|c|c|}
\hline Layer & \multicolumn{1}{|c|}{ Parameters } & Glyphosate $\dagger$ & S-metolachlor \\
\hline \multirow{5}{*}{} & $k_{1 \mathrm{p}}\left(\mathrm{d}^{-1}\right)$ & Adsorption rate of parent molecule & 0.0630 & 0.0630 \\
\cline { 2 - 4 } & $k_{2 \mathrm{p}}\left(\mathrm{d}^{-1}\right)$ & Desorption rate of parent molecule & 0.2142 & 0.0790 \\
\cline { 2 - 4 } & $k_{1 \mathrm{~m}}\left(\mathrm{~d}^{-1}\right)$ & Adsorption rate of metabolite & 0.0011 & 0.0200 \\
\cline { 2 - 4 } & $k_{2 \mathrm{~m}}\left(\mathrm{~d}^{-1}\right)$ & Desorption rate of metabolite & 0.0018 & 0.0270 \\
\cline { 2 - 4 } & $D_{r \mathrm{p}}\left(\mathrm{d}^{-1}\right)$ & Degradation rate of parent molecule & 0.0300 & 0.0100 \\
\cline { 2 - 4 } & $D_{\mathrm{m}}\left(\mathrm{d}^{-1}\right)$ & Degradation rate of metabolites & 0.0600 & 0.0020 \\
\cline { 2 - 5 } & $F_{r b \mathrm{p}}\left(\mathrm{d}^{-1}\right)$ & $\begin{array}{l}\text { NER formation rate from parent molecule (biological } \\
\text { activity) }\end{array}$ & 0.0200 & 0.0010 \\
\cline { 2 - 5 } & $F_{r c \mathrm{p}}\left(\mathrm{d}^{-1}\right)$ & $\begin{array}{l}\text { NER formation rate from parent molecule (chemical } \\
\text { reactivity) }\end{array}$ & 0.0000 & 0.0000 \\
\cline { 2 - 5 } & $F_{r b \mathrm{~m}}\left(\mathrm{~d}^{-1}\right)$ & NER formation rate from metabolite (biological activity) & 0.0035 & 0.0001 \\
\cline { 2 - 5 } & $F_{r c \mathrm{~m}}\left(\mathrm{~d}^{-1}\right)$ & NER formation rate from metabolite (chemical reactivity) & 0.0000 & 0.0000 \\
\hline \multirow{5}{*}{ Soil } & $k_{1}\left(\mathrm{~d}^{-1}\right)$ & Adsorption rate of pesticide & 0.0600 & 0.0340 \\
\cline { 2 - 4 } & $k_{2}\left(\mathrm{~d}^{-1}\right)$ & Desorption rate of pesticide & 0.0040 & 0.0350 \\
\cline { 2 - 4 } & $F_{r b}\left(\mathrm{~d}^{-1}\right)$ & Non-extractable residue formation rate & 0.0004 & 0.0120 \\
\cline { 2 - 4 } & $F_{r c}\left(\mathrm{~d}^{-1}\right)$ & Non-extractable residue de-formation rate & 0.0000 & 0.0000 \\
\cline { 2 - 4 } & $D_{r}\left(\mathrm{~d}^{-1}\right)$ & Degradation rate of parent molecule & 0.1200 & 0.0015 \\
\hline
\end{tabular}

$\dagger$ Aslam et al. (2014)

\title{
2.3.2 Input parameters obtained from the calibration of the column experiments
}

\author{
a. Initial and boundary conditions
}


The PASTIS model was used for the $25-\mathrm{cm}$ soil columns covered by mulch residues that were described in section 2.2.2. The depth was set to 0 at the soil-mulch interface and was designated the upper boundary. A flux-type boundary condition (Neuman-type) was used, and rainfall intensity and surface evaporation were set as the upper boundary conditions for water. At $25 \mathrm{~cm}$ depth, zero water flux without imposing any pressure head was set as the lower boundary condition. Temperature was fixed to $20{ }^{\circ} \mathrm{C}$ in the entire column. The equations of PASTIS were solved using the finite difference method with a node spacing of $0.5 \mathrm{~cm}$ and a time step between 0.001 and $360 \mathrm{~s}$. Wash-off from mulch and transport down to $25 \mathrm{~cm}$ deep soil was simulated, and the $25 \mathrm{~cm}$ deep soil was divided into two layers because of soil sampling at different depths. Simulation in the soil profile was made in two layers: 0-5 and 5-25 cm, which had bulk densities of 1.3 and $1.5 \mathrm{~g} / \mathrm{cm}^{3}$, respectively. Mulch residues were $3 \mathrm{~cm}$ thick on the soil surface. Initial model inputs were derived from measurements that were made at the beginning of the experiment (i.e., at the day 1 sampling). The initial water condition was fixed to a constant volumetric water content $\theta=0.355 \mathrm{~m}^{3} \mathrm{~m}^{-3}$ for the two soil layers. S-metolachlor and glyphosate were applied in solution of $10 \mathrm{ml}$ at $0.193 \mathrm{~g} \mathrm{~L}^{-1}$ and $0.24 \mathrm{~g} \mathrm{~L}^{-1}$, respectively. The biochemical composition of mulch that was determined at d0 was used as the initial condition of the organic pool (RDM, HEM, CEL and LIG). The mulch contained 26.5\%, 35.3\%, $11.9 \%$ and $26.3 \%$ of RDM, HEM, CEL and LIG, respectively. The initial amount of zymogenous biomass C was estimated to be $25 \%$ of the total microbial biomass C as proposed (22\%) by Garnier et al. (2003).

\section{b. Calibration of hydraulic parameters of soil and mulch}

We estimated the hydraulic parameters of mulch and soil from HI-R treatment using the experimental data for matric potentials and volumetric water contents registered at 3 and $15 \mathrm{~cm}$ depths and the gravimetric water content of the mulch. Data from the LF-R treatment were used to test the model with the estimated parameters. The estimated parameters of the hydraulic properties of soil that were described by Van Genuchten's model (van Genuchten, 1980) and were presented in Table S3 of Supplementary Material. Maximum water content, minimum water content and the density of mulch particles were adopted from Iqbal et al. (2013). 
Table 3. Physical parameters of the Mulch module of the PASTIS Model.

\begin{tabular}{|l|l|l|l|}
\hline Symbols & Description of model parameters & Values & Units \\
\hline$\% M C$ & Initial proportion of mulch dry mass in soil contact & $20^{(1)}$ & $\%$ \\
\hline$\alpha_{f e e d}$ & Mulch feeding rate & $0.01^{(1)}$ & $d^{-1}$ \\
\hline$\theta_{\max }$ & Maximal volumetric water content of mulch particles & $0.42^{(2)}$ & $\mathrm{cm}^{3} \mathrm{~cm}^{-3}$ \\
\hline$\theta_{\min }$ & Residual volumetric water content of mulch particles & $0.03^{(2)}$ & $\mathrm{cm}^{3} \mathrm{~cm}^{-3}$ \\
\hline$\alpha$ & Mulch propensity to water recharge & $2^{(1)}$ & \\
\hline$Z_{m, z y b}$ & Depth for available N for mulch decomposition & $5^{(1)}$ & $\mathrm{cm}$ \\
\hline$\epsilon$ & Coefficient of water evaporation & $1.8^{(1)}$ & \\
\hline$B_{\mathrm{nc}}$ & Beer extinction coefficient & $0.75^{(1)}$ & \\
\hline
\end{tabular}

' estimated by the model using HI-R treatment

2 measured (Iqbal et al., 2013)

\section{c. Calibration of pesticide leaching parameters}

Parameters related to pesticide wash-off were estimated in order to simulate the remaining pesticide in mulch after each rainfall event. These parameters, namely, the diffusion coefficient $\left(D_{\mathrm{p}}\right)$ and the saturation index $\left(S_{\mathrm{i}}\right)$, were first calibrated for the HI-R regime and for $\mathrm{S}$ metolachlor. Optimization was done using the amount of available pesticide (in solution and weakly adsorbed) that was measured from mulch residues after each rain. These data were compared to the simulated fractions $P_{\mathrm{w}}$ and $P_{\text {ads }}$ that were calculated by the model on the same days. After obtaining the parameter values, we tested them for the LF-R regime. Similarly, parameters were tested for the glyphosate molecule for the two rain regimes.

\subsubsection{Model evaluation}

The PASTIS model was tested with the HI-R treatment by using the estimated parameters of water flow (Table S3: Supplementary Material), mulch decomposition (Table 2) and pesticide dynamics (Table 3). We simulated pesticide dynamics in mulch and soil, and we tested the model in the LF-R regime conditions using the same estimated parameters. In addition, the Nash efficiency was used to assess the performance of the model as follows:

$$
E_{f}=\frac{\sum_{i=1}^{n}\left(o_{i}-\bar{o}\right)^{2}-\sum_{i=1}^{n}\left(o_{i}-s_{i}\right)^{2}}{\sum_{i=1}^{n}\left(o_{i}-\bar{o}\right)^{2}}
$$


where $o_{i}$ and $s_{i}$ are the observed and simulated values for a given variable, respectively, whereas $\bar{o}$ is the average of $n$ observed values. For each pesticide molecule, efficiency coefficients were determined for the pesticide quantities that remained in the mulch and soil.

\subsubsection{Sensitivity analysis}

A one-at-a-time sensitivity analysis was conducted to test the model behaviour for the parameters and experimental conditions. The effect of individual changes of parameters related to pesticide wash-off (i.e., diffusion rate, $D_{\mathrm{p}}$, saturation index, $S_{\mathrm{i}}$ and the time of the first rain after pesticide application), the mulch physical parameters (proportion of mulch in contact with soil, \%Mc) and pesticide transformation in mulch (adsorption coefficient, $\mathrm{k}_{1 \mathrm{p}}$, degradation coefficient, $D_{r p}$, formation rate of NER, $F_{r b p}$ ) on simulated values of the output variables (NER, degraded and wash-off fractions) was performed for both pesticides (glyphosate and Smetolachlore) with an infrequent rainfall (HI-R) treatment. Each parameter was modified by a $20 \%$ increase and $20 \%$ decrease of its original value. Moreover, the effect of timing of the first rainfall was also tested on the same output variables by applying the first rain after 10 days instead of the first day. The sensitivity coefficient, $\sigma$, to each parameter was calculated as follows:

$$
\sigma_{20 \%}=\frac{1}{t_{f}} \int_{0}^{t_{f}} \frac{X_{c}-X_{o}}{X_{o}} \times d t
$$

where $t_{f}$ is the test duration (20 or 84 days), $X_{c}$ is the simulated value that is predicted by the model when the value of the parameter was changed from the default value by $\pm 20 \%$, and $X_{o}$ is the simulated value that is predicted by the model with the default value of the parameter.

\section{Results and Discussion}

\subsection{Modelling water flow in mulch and soil}

The simulated water content of mulch residues (simulated using the parameters in Table 3) increased rapidly during rain applications and then decreased gradually during the evaporation 
period. Mulch water contents were quite similar during all drying and wetting cycles for the frequent regime. Findeling et al. (2007) reported an increase in the water retention of mulch during the experiment as decomposition proceeded, which they attributed to an increase in porosity due to cell wall degradation. In our study, the absence of an increase in water retention capacity of the mulch after rain application could be explained by a lower decomposition of residues at end of the experiment compared to the decomposition that was described by Findeling et al. (2007). Mulch residues remained wetter in the case of the light and frequent rain regime (LF-R) when rains occurred every three days, and residues dried to a smaller extent because of the shorter evaporation period. In contrast, residues were always drier in the heavy and infrequent rain regime (HI-R). Because rains in this regime occurred every fourteen days, residues dried more during the longer period of evaporation. The model simulated the water dynamics of mulch well for the heavy and infrequent regime (Figure 3 ), with $E_{\mathrm{f}}=0.78$. This is because the model was calibrated using the data from this treatment. However, the efficiency of model simulations was less satisfactory for the light and frequent regime $\left(E_{\mathrm{f}}=0.36\right)$.
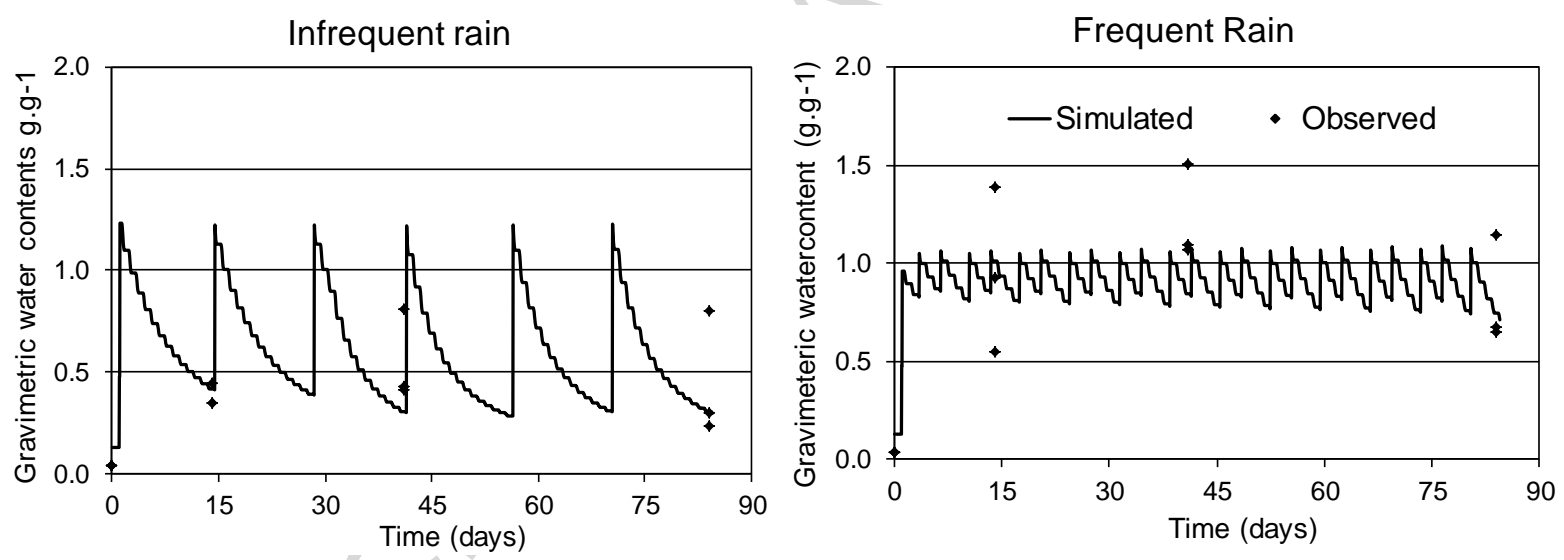

Figure 3. Simulations of water dynamics in mulch residues for the two rain regimes.

In soil, the simulated water contents were different for the two rain regimes (Fig. S2). In the infrequent regime (rains occurred every 14 day), we observed a greater dryness of soil during evaporation periods, especially in the top layer. In the frequent regime, columns were near saturation at all times, and there was no variation in water content and matric potential during the evaporation period.

\subsection{Modelling mulch decomposition}


Rainfall regime had a strong effect on mulch decomposition and on the subsequent quality of mulch organic matter (Iqbal et al., 2015). The organic carbon content of the mulch decreased during decomposition for the two rain treatments. However, it decreased more in the case of frequent rainfalls (LF-R) compared to infrequent rainfalls (HI-R) because of the more humid conditions at the soil-mulch interface due to smaller evaporation periods in the LF-R treatment compared to the HI-R treatment. PASTIS simulated the two different decomposition dynamics well, with efficiency coefficients of 0.16 and 0.85 (Table 5) for light and frequent and heavy and infrequent regimes, respectively. The evolution of mulch biochemical composition was also simulated with the Cantis model (the $\mathrm{C} / \mathrm{N}$ module of PASTIS), which was calibrated using the parameters presented by Iqbal et al. (2014). The model correctly simulated the global C massloss of mulch in the HI-R treatment but over-estimated the C loss in the LF-R treatment after 45 days (Figure 4). All pools (RDM, HEM, CEL and LIG) were better simulated for the HI-R treatment (with $\mathrm{EF}=0.85$ ) compared to the $\mathrm{LF}-\mathrm{R}$ treatment (with $\mathrm{EF}=0.16$ ), especially the $\mathrm{RDM}$ and cellulosic pools of LF-R that were underestimated by the model for the last date (day 84). Because the model was calibrated with HI-R and tested with LF-R, the quality of the prediction was better with HI-R. The soluble carbon that is contained in the RDM fraction may be submitted to a too high leaching by the model.
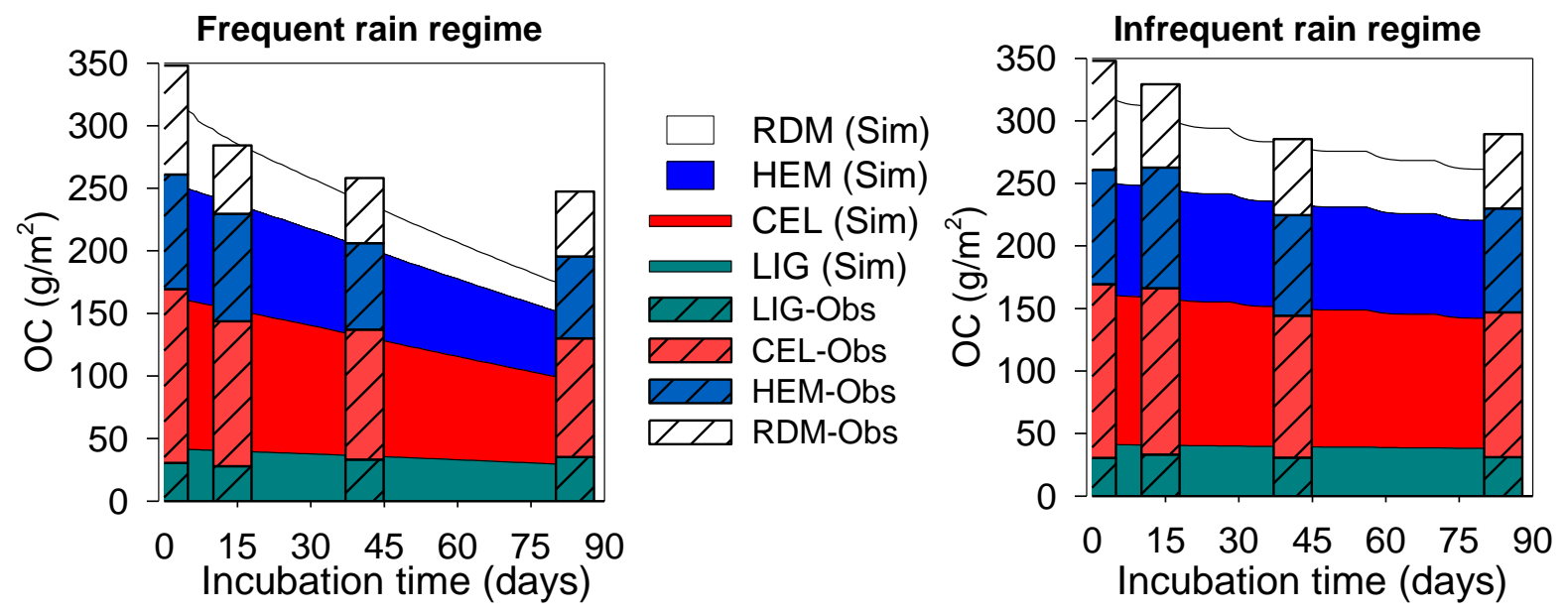

Figure 4. Comparison between experimental data and simulations of the evolution of the biochemical composition of mulch for the two rain regimes (HI-R and LF-R). 


\subsection{Modelling pesticide dynamics in mulch}

The pesticide concentrations in the mulch and soil layers were simulated. The model correctly simulated these dynamics while using the parameters of degradation and sorption that were estimated through independent incubations. Technical details were reported by Aslam et al. (2014) for glyphosate and are presented in Figure S1 for s-metolachlor. Figure 5 shows the comparison of pesticide quantities (sum of soluble and adsorbed pools) that was measured experimentally at each destructive sampling phase with pesticide quantities simulated by the model. We simulated these dynamics by estimating parameters related to pesticide wash-off. The water diffusion $\left(D_{\mathrm{p}}\right)$ and saturation index $\left(S_{\mathrm{i}}\right)$ were calibrated using the heavy and infrequent rain regime (HI-R). The optimal value for the simulation was 1.2 for $D_{\mathrm{p}}\left(\mathrm{day}^{-1}\right)$ and $0.58 \mathrm{~cm}^{3} \mathrm{~cm}^{-3}$ for $S_{\mathrm{i}}$. After achieving good agreement between the simulated and observed values in the infrequent rain regime (HI-R), we evaluated the simulation for the frequent rain regime (LF-R). We found that the amount of pesticides mainly decreased after each rainfall event and remained stable between rains. We observed a higher decrease of pesticide amounts after the rains of the HI-R treatments compared to the LF_R treatments, where the decrease was more progressive. The difference between treatments was due to pesticide leaching by the rain. S-metolachlor in mulch, however, was better simulated than glyphosate in mulch with greater efficiency coefficients for S-metolachlor $\left(E_{\mathrm{f}}=96\right.$ and 0.7 for HI-R and LF-R, respectively) than for glyphosate $\left(E_{\mathrm{f}}=0.53\right.$ and 0.50 for HI-R and LF-R, respectively) (Table 5).

Table 4. Optimal value of statistical performance (efficiency coefficient) of the calibrated model.

\begin{tabular}{|c|c|c|c|c|c|}
\hline & Heavy and Infrequent Rainfall & \multicolumn{2}{|c|}{ Light and Frequent Rainfall } \\
\hline$\theta_{\text {mulch }}$ & \multicolumn{2}{|c|}{0.78} & \multicolumn{2}{c|}{0.36} \\
\hline Mulch C & \multicolumn{2}{|c|}{0.85} & \multicolumn{2}{c|}{0.16} \\
\hline & S-metolachlor & Glyphosate & S-metolachlor & Glyphosate \\
\hline Pesticide $_{\text {mulch }}$ & 0.96 & 0.53 & & 0.7 & 0.5 \\
\hline Pesticide $_{\text {soil }}$ & 0.57 & -0.66 & & 0.51 & -0.66 \\
\hline
\end{tabular}

The amount of glyphosate remaining in the mulch was underestimated by the model at the end of the experiment. Aslam et al. (2013) found that desorption of glyphosate from fresh mulch residues was small and increased with the degree of decomposition. We may have overestimated the desorption rate and it is possible that some portion of the applied glyphosate was trapped by vegetal cell walls and could not be leached downward as suggested by Rampoldi et al. (2011). 

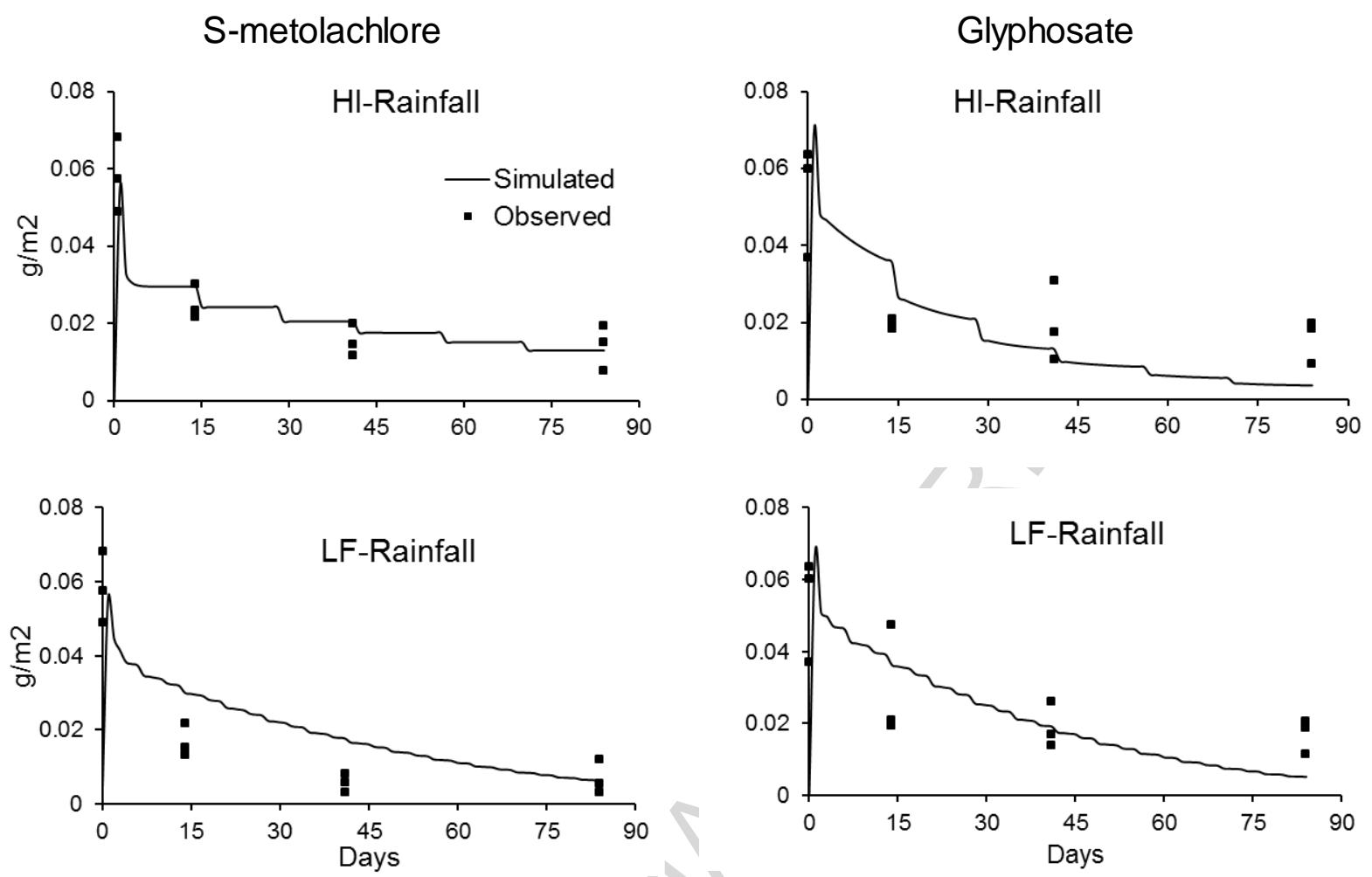

Figure 5. Remaining pesticide amounts in mulch residues. Solid lines show simulated values (sum of soluble and adsorbed fractions).

\subsection{Modelling pesticide dynamics in soil columns}

Pesticide quantities were also simulated in soils using the estimated parameters from independent incubations (Table 3). S-metolachlor was better simulated than glyphosate and the efficiency coefficients of S-metolachlor were satisfactory for two rain treatments (Table 4). Specifically, the model was able to simulate the S-metolachlor in the soil layer below the mulch well (Fig. 6). For glyphosate, analytical difficulties for accurately measuring the glyphosate concentration values in soil and mulch appeared. Due to analytical difficulties, we suspect that glyphosate was not totally recovered from soil, as was previously assumed by Aslam et al. (2015). At d 1, almost half of the applied quantity (55\%) was recovered from the mulch, and $45 \%$ entered the soil layer due to glyphosate wash-off (Table 5). However, we could only measure less than 6\% of the applied glyphosate in the soil. The poor mass-balance of glyphosate resulted in bad simulations and a poor efficiency coefficient (Figure 6, Table 4). However, glyphosate was rapidly degraded 
in soil and smaller glyphosate quantities were recovered at $14 \mathrm{~d}$ sampling, and almost no glyphosate was measured in soil at 42 and $84 \mathrm{~d}$ of sampling because of its faster degradation rates that were estimated from incubation. With the model, we simulated greater amount of glyphosate in soil just after the rain with the infrequent regime compare to the frequent regime that was attributed to greater losses from the mulch by wash-off. The simulated concentrations of S-metolachlor and glyphosate were very different in terms of kinetics (Figure 6). Indeed the desorption rate of glyphosate (Table 2) was much higher than that of S-metolachlor, it was therefore more easily leached by water at each rain event.

S-metolachlore
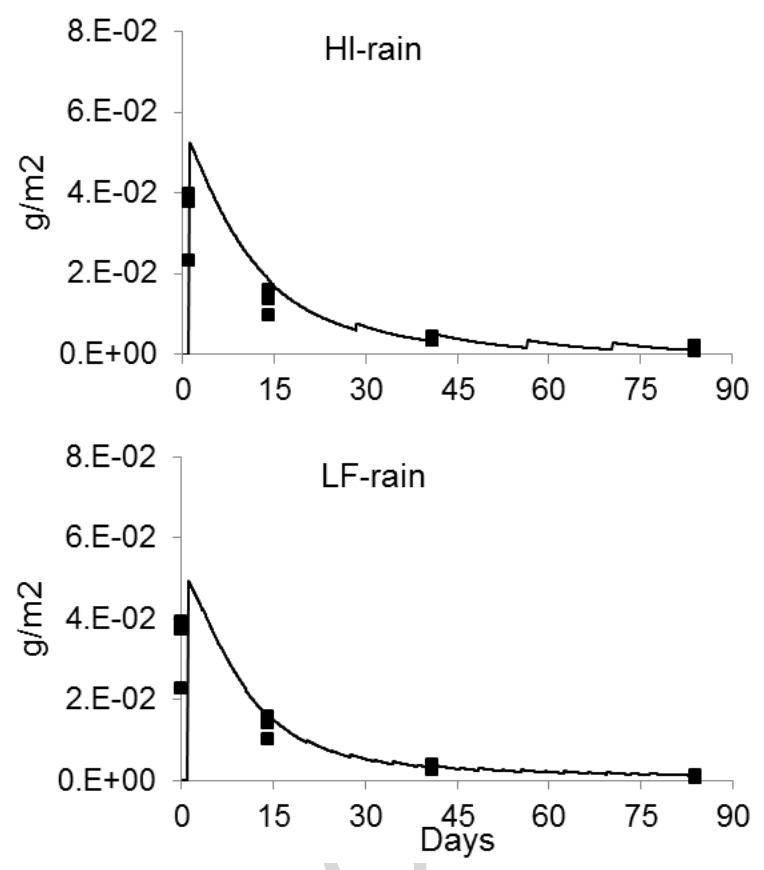

Glyphosate
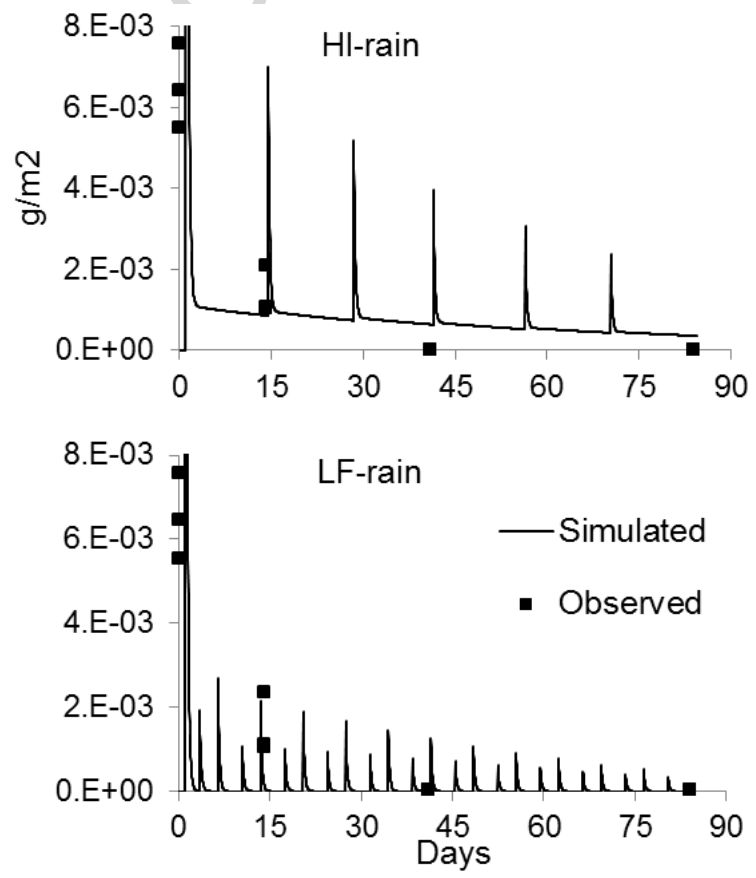

Figure 6. Comparison between simulated and measured S-metolachlor and glyphosate quantities in $0-5 \mathrm{~cm}$ soil layers.

\subsection{Modelling Pesticide wash off and mass balance}

The model simulations suggested that the rain regime affected the pesticide losses through washoff (Figure 7). This amount would have been difficult to measure experimentally. As expected, wash-off under both rain regimes was greater after rain application in the early days of the experiment because the effect of rainfall intensity on pesticide wash-off is considered to be important after the first rain application (Granovsky et al., 1994). The cumulative loss of 
pesticides through wash-off was greater for the infrequent rain regime (Figure 7) for both molecules. The frequent rain regime with a lighter rain intensity resulted in a smaller pesticide wash-off from the mulch. The model showed that the pesticides did not leach in the same way. We observed more leaching of glyphosate than S-metolachlor. This difference can be related to the adsorption characteristics of the two molecules on the mulch residues, in which there is a greater desorption of glyphosate compared to S-metolachlor (Table 2).
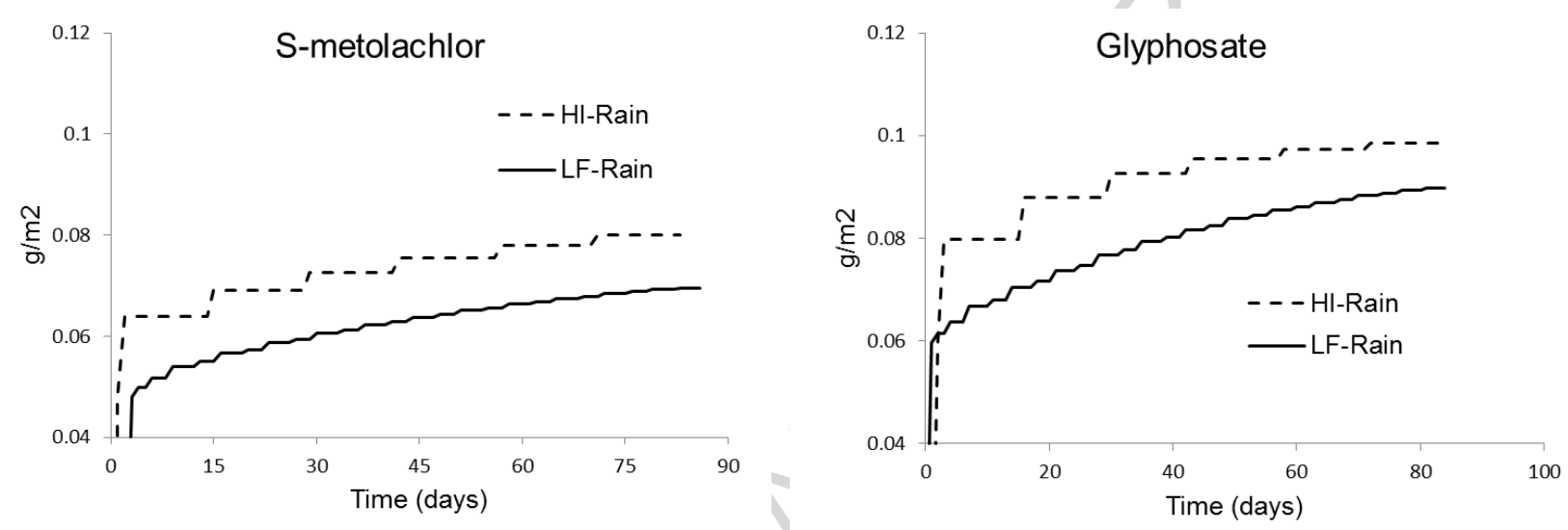

Figure 7. Cumulative pesticide wash-off from mulch obtained from the model simulations. Symbols HI-R and LF-R represent heavy and infrequent and light and frequent rain regimes, respectively.

The model predicted pesticide partitioning between leaching (45-46\%) and mulch interception (54-55\%) on day 1 (Table 5) for both pesticides. Despite the difference in their adsorptiondesorption parameters (Table 2), the molecules were equally distributed at day 1 with the model after their application at the surface. The absence of differences could be explained i) by the fact that the pesticides concentration were calculated (and measured) just after their application resulting in similar diffusion into mulch and wash-off and ii) because they just had the time to adsorb with similar adsorption kinetic parameters (Table 2) (even if their desorption rates were different, they did not have the time to desorb).

The model also simulated the fate at day 84 of the remaining pesticide in mulch residues at d1 (leaching, adsorption, degradation and NER formation) (Table 5). The simulated distribution of the remaining pesticide at day 84 showed that glyphosate was more degraded than Smetolachlor, as estimated from incubation experiments. Faster glyphosate degradation has been reported by many studies (e.g., Accinelli et al., 2005) and was already observed compared to the 
results of Aslam et al. (2014a) and those in Figure S1. Lower desorption coefficients for the smetolachlore molecule (Table 2) explained the greater amount that was retained in mulch compared to glyphosate, which was more easily desorbed. According to the assumption of our model, degradation occurs in the soluble pool, so greater glyphosate degradation was expected. This simulated result agrees with previous results that were reported by Aslam et al. (2013), who demonstrated greater adsorption capacities of mulch residues for the non-ionic molecule Smetolachlor compared to glyphosate, which is a highly soluble molecule. The adsorption parameter for glyphosate that was estimated by Aslam et al. (2014) was also smaller compared to S-metolachlor (Table 3). In the similar way, the formation of NER was slightly greater for smetolachlor than for glyphosate, as already observed during incubations compared to the results of Aslam et al. (2014) and Figure S1. However, we observed that the dynamics of pesticide degradation and NER formation were different from those that were estimated in the incubation experiments. As a result, the model simulated comparatively less glyphosate degradation in the mulch than was measured in the static incubation experiment, as reported by Aslam et al. (2014) for glyphosate and as shown in Figure S1 for S-metolachlor. We assume that pesticide wash-off by rainfall application could have impacted these dynamics. In addition, another parameter used in the model that could have greatly impacted degradation, and NER formation was the proportion of the mulch mass that was in contact with the soil. In our model, we assumed that microorganisms fed only on plant residues that were in immediate contact with the soil surface. We optimized a proportion of $20 \%$ of mulch mass being in contact with soil surface while modelling mulch decomposition in our columns. That means that $20 \%$ of the pesticide amount that was retained by the mulch layer was available for biodegradation and NER formation in the mulch. This interpretation was also supported by results of the sensitivity analyses. 
Table 5. Simulated mass-balance of pesticides (in \%) in the soil column at day 1 and fate at day 84 of intercepted pesticides in mulch residues at day 1

\begin{tabular}{|c|c|c|c|c|}
\hline & \multicolumn{2}{|c|}{ S-metolachlore } & \multicolumn{2}{c|}{ Glyphosate } \\
\hline & HI-R & LF-R & HI-R & LF-R \\
\hline & \multicolumn{2}{|c|}{ Percentage of pesticide in the soil column at time day 1 } \\
\hline $\begin{array}{c}\text { Intercepted by } \\
\text { Mulch* }\end{array}$ & \multicolumn{2}{|c|}{$55 \%$} \\
\hline $\begin{array}{c}\text { Leached below } \\
\text { mulch }\end{array}$ & \multicolumn{2}{|c|}{$46 \%$} & \multicolumn{2}{c|}{$45 \%$} \\
\hline & Fate at day 84 of pesticide intercepted by the mulch at time day 1 & $45 \%$ \\
\hline Leached & $56 \%$ & $39 \%$ & $57 \%$ & $45 \%$ \\
\hline Degraded & $17 \%$ & $37 \%$ & $37 \%$ & $4 \%$ \\
\hline NER & $4 \%$ & $13 \%$ & $3 \%$ & $5 \%$ \\
\hline soluble & $2 \%$ & $1 \%$ & $4 \%$ & $1 \%$ \\
\hline adsorbed & $21 \%$ & $10 \%$ & $1 \%$ & \multicolumn{2}{c|}{} \\
\hline
\end{tabular}

*Present in mulch as soluble, adsorbed or NER fractions

\subsection{Sensitivity analysis of the model to mulch parameters}

The results of the sensitivity analysis of the model to input parameters and initial conditions are presented in Figure 8 for the following pesticide output: washed-off, NERs and degraded quantities present in mulch residues at two times (days 20 and 84). A sensitivity analysis was performed for both pesticide molecules with infrequent rain (HI-R) treatment. The parameters are linked to mulch characteristics, the rain application and to the pesticide transformation in mulch.

The most sensitive parameter for all output variables was the mulch saturation index $\left(S_{\mathrm{i}}\right)$ related to the starting point for pesticide diffusion from mulch to rain water (Eq. 4). This parameter affected not only wash-off but also the NER and degraded pools. The time of the first rainfall $\left(R_{1}\right)$ was the second most sensitive parameter; it affected mainly wash-off and degradation and less NER formation. Timing of the first rain is widely reported to affect pesticide dynamics in soils (e.g., Granovsky et al., 1994 ; Lindhal et al., 2005). Dusek et al. (2010) evaluated the impact of mulch on water dynamics and the bromacil concentration in the soil on a pineapple plantation using models. They also found that rainfall intensity played a major role in bromacil leaching in soil. The diffusion coefficient between the water of mulch and the rain water $D_{\mathrm{p}}$ (Eq. 4) was the third most sensitive parameter, but only for pesticide wash-off. For the other two 
outputs (NERs and degraded pools), the third most sensitive parameter was the proportion of mulch in contact with the soil $(\% \mathrm{Mc})$ that contained an amount of pesticide that was potentially available for microbial transformations.

In our study, the parameters that were directly linked to the transformation of pesticides in mulch (e.g., the parameters of degradation, adsorption and formation of NER) did not significantly impact the outputs of the model. The NER compartment was more sensitive to these parameters than the two other outputs. More recently, Queyrel et al. (2016) tested a crop model, STICS, after adding a pesticide module to study different agricultural management practices on pesticide dynamics in soil. Their STICS-Pest model simulated the dynamics of three pesticides. They found that pesticide flux in soil was more sensitive to degradation and adsorption parameters, but they did investigate the pesticides in mulch.

We tested the model sensitivity for two durations (i.e., short term (20 days) and long term (84 days, end of experiment)). Despite the fact that the pesticide concentrations in the different compartments were quite different, between 20 and 84 days (Fig 5,6,7), the sensitivity to the parameters was quite close between these two days except for the parameter R1 (Figure 8). The sensitivity of the model outputs to parameters was quite similar for both pesticide molecules as shown in figure 8. 

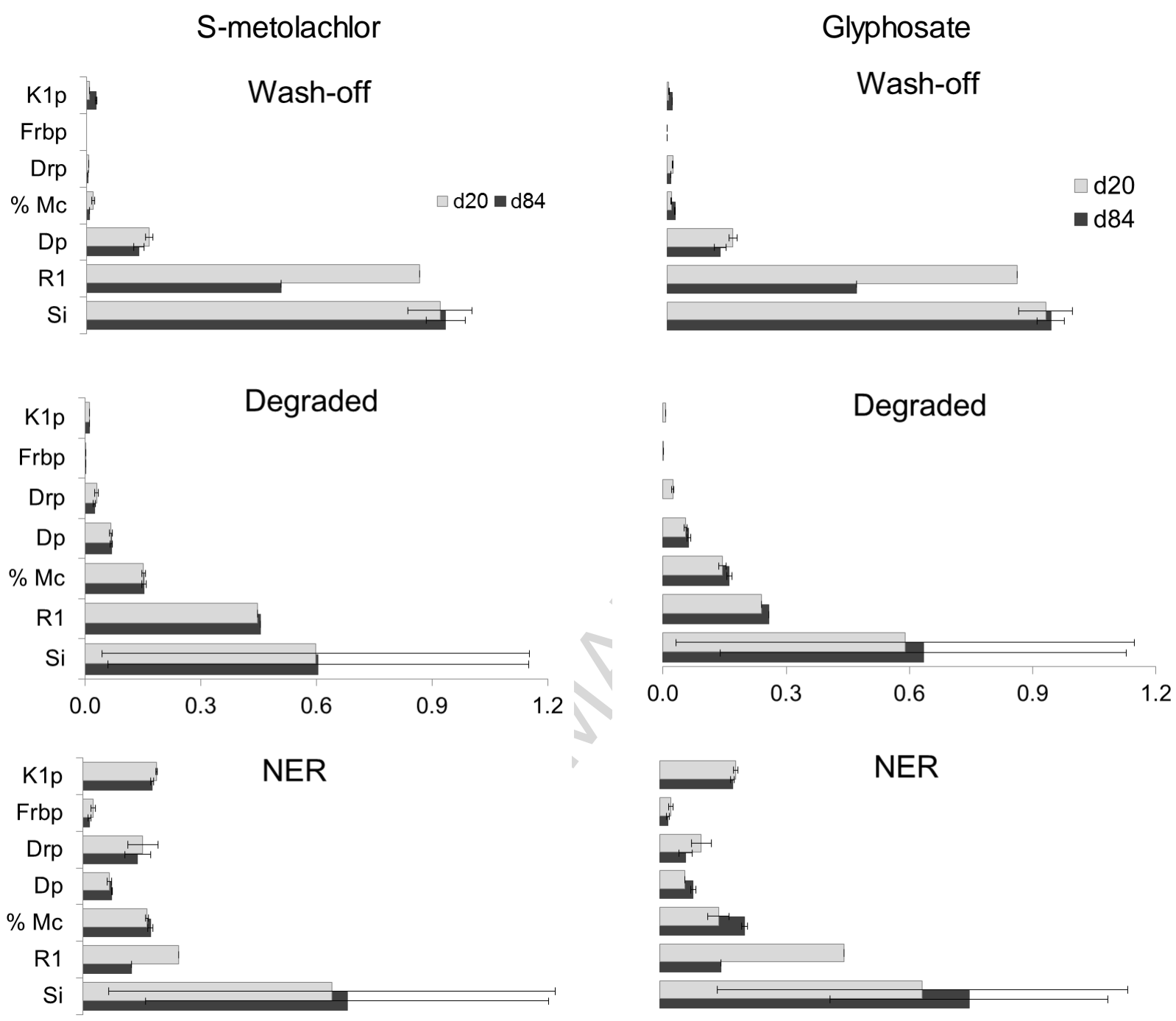

Figure 8. Sensitivity coefficients of the PASTIS to model parameters in the HI-R treatment. Histograms show means $\pm S D$. $k_{1 p}$ : adsorption rate of the parent molecule $\left(\mathrm{d}^{-1}\right), \mathrm{D}_{\mathrm{rp}}$ : degradation rate of the parent molecule $\left(\mathrm{d}^{-1}\right), \mathrm{F}_{\mathrm{rbp}}$ : NER formation rate from the parent molecule by biological activity $\left(\mathrm{d}^{-1}\right), D_{p}$ : coefficient of diffusion from mulch to rain water $\left(\mathrm{d}^{-1}\right), S_{i}$ : the saturation index of mulch from which diffusion of the pesticide can occur $\left(\mathrm{cm}^{3} \mathrm{~cm}^{-3}\right), R_{1}$ : time between the pesticide application and the first rainfall $\left(\mathrm{d}^{-1}\right), \% \mathrm{MC}$ : initial proportion of mulch dry mass in soil contact. 


\section{Conclusions}

To our knowledge, very few studies have been done to simulate pesticide dissipation in mulch residues and the underlying soil. We proposed a new model for predicting pesticide dissipation in mulch and soil that combined "pesticide" and "mulch" modules. The model accounted for both transport and biological processes involved in pesticide fate during mulch decomposition. The study was conducted to test the model in soil columns under different rainfall regimes. The pesticide module in PASTIS was satisfactory for simulating the dynamics of two different types of herbicides. Parameters estimated from laboratory incubations under static conditions were useful for predicting pesticide transformation in soil columns. Satisfactory simulation results indicated that pesticide wash-off is dependent on pesticide characteristics $(39-56 \%$ for smetolachlor and $45-57 \%$ for glyphosate). Simulations have also shown the effects of different rainfall patterns on pesticide wash-off from mulch residues, with higher leaching for high and infrequent intensity compare to light and frequent intensity for both pesticides (56\% versus 39\% for s-metolachlor and $57 \%$ versus $45 \%$ for glyphosate). From the parameter sensitivity analysis, the two parameters that were linked to diffusion between rain water and mulch water were among the most sensitive parameters and affected the model outputs. In addition, the time of the first rainfall after pesticide application greatly affected pesticide leaching and dissipation. Great attention should be paid to measure this variable in future studies in order to accurately evaluate the amount of pesticide that leaves the sub-surface and potentially contaminates the groundwater in conservation agriculture. 


\section{Acknowledgements}

This work was carried out with the support of the PEPITES project funded by the French Agency for Research, and the doctoral fellowship of Sohaib Aslam was supported by the Higher Education Commission (HEC) of Pakistan. 


\section{References}

Accinelli, C; Koskinen, WC; Seebinger, JD; Vicari, A Sadowsky, MJ., 2005. Effects of incorporated corn residues on glyphosate mineralization and sorption in soil. Journal of Agricultural and Food Chemistry 53 (10), 4110-4117

Alletto, L., Coquet, Y., Benoit, P., Heddadj, D., Barriuso, E., 2010. Tillage management effects on pesticide fate in soils. A review. Agronomy for Sustainable Development 30,367-400.

Alletto, L, Benoit, P, Bolognesi, B, Couffignal, M, Bergheaud, V, Dumeny, V, Longueval, C, Barriuso, E. 2013. Sorption and mineralisation of S-metolachlor in soils from fields cultivated with different conservation tillage systems. Soil \& Tillage Research, 128, 97103.

Aslam, S., Garnier, P., Rumpel, C., Parent, S.E., Benoit, P., 2013. Adsorption and desorption behavior of selected pesticides as influenced by decomposition of maize mulch. Chemosphere 91, 1447-1455.

Aslam, S., Benoit, P., Chabauty, F., Bergheaud, V., Geng, C., Vieublé-Gonod, L., Garnier, P., 2014. Modelling the impacts of maize decomposition on glyphosate dynamics in mulch. European Journal of Soil Science 65, 231-247.

Aslam, S., Iqbal, A., Deschamps, M., Recous, S., Garnier, P., Benoit, P., 2015. Effect of rainfall regimes and mulch decomposition on the dissipation and leaching of S-metolachlor and glyphosate: a soil column experiment. Pest Management Science 71, 278-291.

Brimo, K., Ouvrard, S., Houot, S., Lafolie, F., Garnier, P., 2018. Modelling the fate of PAH added with composts in amended soil according to the origin of the exogenous organic matter. Science of the Total Environment,https://doi.org/10.1016/j.scitotenv.2017.10.269

Coppens, F., Garnier, P., Findeling, A., Merckx, R., Recous, S., 2007. Decomposition of mulched versus incorporated crop residues: Modelling with PASTIS clarifies interactions between residue quality and location. Soil Biology \& Biochemistry 39, 2339-2350.

Dao, T.H., 1991. Field decay of wheat straw and its effects on metribuzin and s-ethyl metribuzin sorption and elution from crop residues. Journal of Environmental Quality 20, 203-208.

Dusek, J., Ray, C., Alavi, G., Vogel, T., Sanda, M., 2010. Effect of plastic mulch on water flow and herbicide transport in soil cultivated with pineapple crop: A modeling study. Agricultural Water Management; 97: 1637-1645. 
Enrique, G.-S., Braud, I., Jean-Louis, T., Michel, V., Pierre, B., Jean-Christophe, C., 1999. Modelling heat and water exchanges of fallow land covered with plant-residue mulch. Agricultural and Forest Meteorology 97, 151-169.

Findeling, A., Chanzy, A., De Louvigny, N., 2003. Modeling water and heat flows through a mulch allowing for radiative and long-distance convective exchanges in the mulch. Water Resources Research 39.

Findeling, A., Garnier, P., Coppens, F., Lafolie, F., Recous, S., 2007. Modelling water, carbon and nitrogen dynamics in soil covered with decomposing mulch. European Journal of Soil Science 58, 196-206.

FOCUS, 2006. "Guidance Document on Estimating Persistence and Degradation Kinetics from Environmental Fate Studies on Pesticides in EU Registration" Report of the FOCUS Work Group on Degradation Kinetics, EC Document Reference Sanco/10058/2005, version $2.0,434 \mathrm{pp}$.

Garnier, P., Neel, C., Aita, C., Recous, S., Lafolie, F., Mary, B., 2003. Modelling carbon and nitrogen dynamics in a bare soil with and without straw incorporation. European Journal of Soil Science 54, 555-568.

Gaston, L.A., Boquet, D.J., Bosch, M.A., 2001. Fluometuron wash-off from cover crop residues and fate in a loessial soil. Soil Science 166, 681-690.

Geng, C., Haudin, C-S, Zhang, Y., Lashermes, G., Houot, S., Garnier ,P. 2015. Modelling the release of organic contaminants during compost decomposition in soil. Chemosphere 119, 423-431.

Gimsing, A.L., Borggaard, O.K., Jacobsen, O.S., Aamand, J. \& Sørensen, J. 2004. Chemical and microbiological soil characteristics controlling glyphosate mineralisation in Danish surface soils. Applied Soil Ecology, 27, 233-242.

Granovsky, A.V., McCoy, E.L., Dick, W.A., Shipitalo, M.J., Edwards, W.M., 1994. Impacts of antecedent moisture and soil surface mulch coverage on water and chemical-transport through a no-till soil. Soil \& Tillage Research 32, 223-236.

Hatier, J., 2012. Fate of ${ }^{14} \mathrm{C}$ S-metolachlor in crop residues and underlying soils. Master thesis ISARA-Lyon-Ecole d'Ingénieurs de PURPAN p. 39.

Iqbal, A., Beaugrand, J., Garnier, P., Recous, S., 2013. Tissue density determines the water storage characteristics of crop residues. Plant and Soil, Plant and Soil, 367 : 285-299. 
Iqbal, A., Garnier, P., Lashermes, G., Recous, S.. 2014. A new equation to simulate the contact between soil and maize residues of different sizes during their decomposition. Biology and Fertility of Soils, $50: 645-655$.

Iqbal, A., Aslam, S., Alavoine, G., Benoit, P., Garnier, P. and Recous, S., 2015. Effects of rain regime and soil type on $\mathrm{C}$ and $\mathrm{N}$ dynamics in soil covered with mixed-species mulches. Plant and Soil, 393: 319-334.

Lammoglia, S.K., Moeys, J., Barriuso, E., Larsbo, M., Marin-Benito, JM., Justes, E., Alletto, L., Ubertosi, M., Nicolardot, B., Munier-Jolain, N., Mamy, L. 217. Sequential use of the STICS crop model and of the MACRO pesticide fate model to simulate pesticides leaching in cropping systems. Environmental Science and Pollution Research 24, 68956909

Lashermes, G., Zhang, Y., Houot, S., Steyer, J.P., Patureau, D., Barriuso, E., Garnier, P., 2013. Simulation of Organic Matter and Pollutant Evolution during Composting: The COPCompost Model. J. Environ. Qual 42, 361-372.

Lindahl, A. M. L., Kreuger, J., Stenström, J., Gärdenäs, A. I., Alavi, G., Roulier, S., Jarvis, N. J. 2005. Stochastic Modeling of Diffuse Pesticide Losses from a Small Agricultural Catchment. J. Environ. Qual, 34:1174-1185

Locke, M.A., Bryson, C.T., 1997. Herbicide-soil interactions in reduced tillage and plant residue management systems. Weed Science 45, 307-320.

Ma, L.W., Selim, H.M., 2005. Predicting pesticide transport in mulch-amended soils: A twocompartment model. Soil Science Society of America Journal 69, 318-327.

Queyrel, W., Habets, F., Blanchoud, H., Ripoche, D., Launay, M., 2016. Pesticide fate modeling in soils with the crop model STICS: Feasibility for assessment of agricultural practices. Science of The Total Environment 542, Part A, 787-802.

Rabary, B., Sall, S., Letourmy, P., Husson, O., Ralambofetra, E., Moussa, N., Chotte, J.L., 2008. Effects of living mulches or residue amendments on soil microbial properties in direct seeded cropping systems of Madagascar. Applied Soil Ecology 39, 236-243.

Rampoldi, A., Hang, S., Barriuso, E., 2008. Glyphosate mineralization: Effect of temperature and soybean and corn crop residues. Chilean Journal of Agricultural Research 68, 13-20.

Rampoldi, A., Hang, S.; Barriuso, E., 2011. The Fate of Glyphosate in Crop Residues. Soil Science Society of America Journal, 75 (2), 553-559 
Saffih-Hdadi, K., Bruckler, L., Barriuso, E., 2003. Modeling of sorption and biodegradation of parathion and its metabolite paraoxon in soil. Journal of Environmental Quality 32, 22072215.

Shelton, DR, Doherty, MA., 1997. A model describing pesticide bioavailability and biodegradation in soil. Soil Science Society of America Journal 61 (4), 1078-1084.

Thorburn, P.J., Probert, M.E., Robertson, F.A., 2001. Modelling decomposition of sugar cane surface residues with APSIM-Residue. Field Crops Research 70, 223-232.

van Genuchten, M.T., 1980. A Closed-form Equation for Predicting the Hydraulic Conductivity of Unsaturated Soils1. Soil Sci. Soc. Am. J. 44, 892-898. 


\section{Graphical Abstract:}
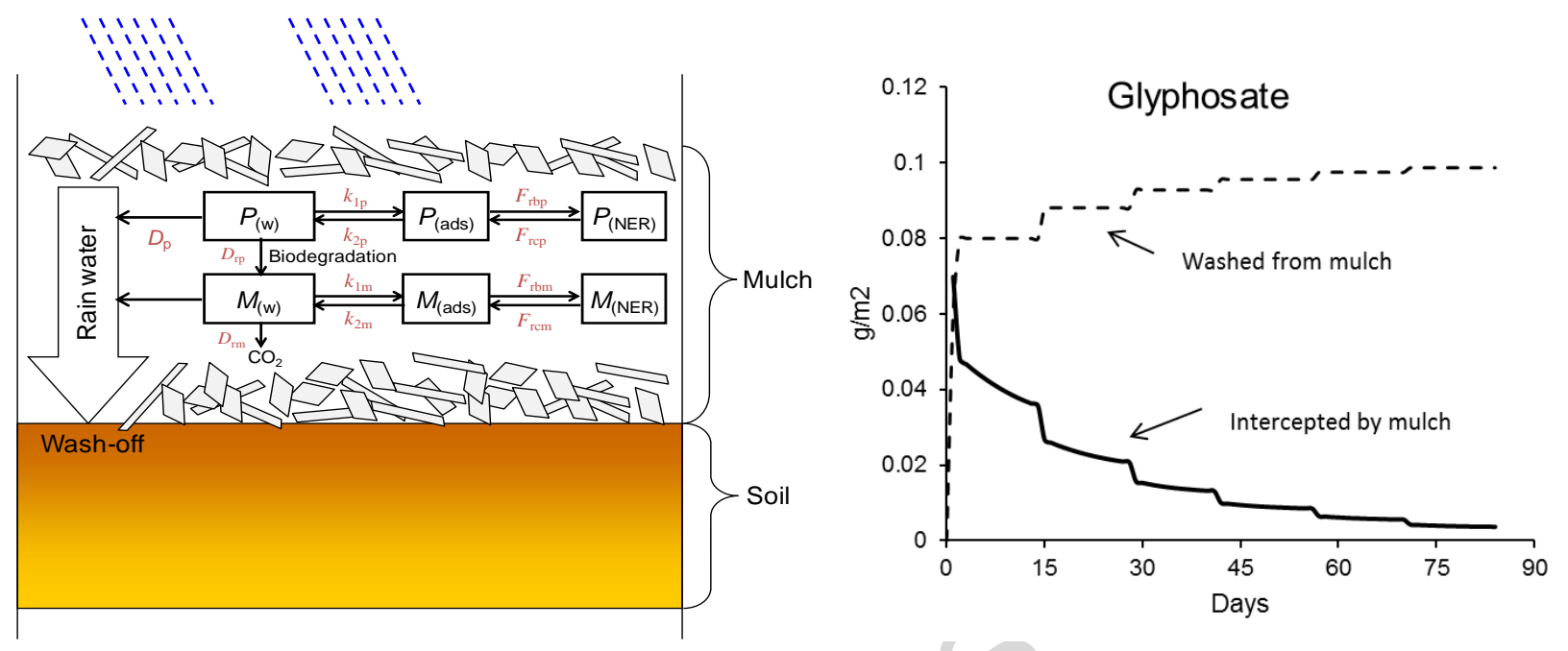


\section{Highlights}

- A new model of pesticide interception by mulch of crop residues is presented

- The model simulates about $55 \%$ of pesticide retention in mulch after the first rain

- Between 39\% and 57\% of remaining pesticides leach below the mulch afterwards

- Pesticide wash-off is greater for high and infrequent rain than for light and frequent rain

- Glyphosate is more degraded than s-metolachlor in mulch 